\title{
Estimates of Prevalence of Pulmonary Hypertension according to Different International Definitions
}

\author{
Richa Tyagi $\mathbb{D}^{1},{ }^{1}$ Surya Kant ${ }^{(D)},{ }^{1}$ Akshyaya Pradhan ${ }^{(D)},{ }^{2}$ Anupam Wakhlu ${ }^{(D)}{ }^{3}$ \\ Darshan Kumar Bajaj $\mathbb{D}^{1},{ }^{1}$ and Jyoti Bajpai ${ }^{1}{ }^{1}$ \\ ${ }^{1}$ Department of Respiratory Medicine, King George's Medical University, Lucknow, UP, India \\ ${ }^{2}$ Department of Cardiology, King George's Medical University, Lucknow, UP, India \\ ${ }^{3}$ Department of Rheumatology, King George's Medical University, Lucknow, UP, India
}

Correspondence should be addressed to Akshyaya Pradhan; akshyaya33@gmail.com

Received 24 July 2021; Accepted 15 November 2021; Published 28 November 2021

Academic Editor: Isabella Annesi Maesano

Copyright ( $\odot 2021$ Richa Tyagi et al. This is an open access article distributed under the Creative Commons Attribution License, which permits unrestricted use, distribution, and reproduction in any medium, provided the original work is properly cited.

Background. Pulmonary hypertension is a dreaded disease associated with considerable morbidity and mortality. The pulmonary hypertension developing due to chronic respiratory disease is a unique subset with symptoms often getting masqueraded by the underlying respiratory condition. The importance of early detection of this complication has been realized worldwide, and recently, the definition of pulmonary hypertension was revised to set the cutoff of mean pulmonary artery pressure (mPAP) at $20 \mathrm{mmHg}$ instead of $25 \mathrm{mmHg}$ at rest. In our study, we have tried to estimate the difference this new definition brings to the prevalence of pulmonary hypertension among interstitial lung disease patients at our centre. Methods. This was a cross-sectional study in which all the patients of ILDs $(n=239)$ attending the outdoor and indoor Department of Respiratory Medicine, King George's Medical University, India, for the duration of one year were subjected to transthoracic echocardiography along with measurement of serum pro-B-type natriuretic peptide (BNP) and troponin T values. The data were analyzed using the different definitions, and the prevalence was compared. Result. Incidence of pulmonary hypertension among ILD patients at mPAP cutoff $\geq 25$ was $28.9 \%$, while that at value $\geq 20 \mathrm{mmHg}$, incidence of pulmonary hypertension increased to $46.0 \%$. An increment of 15-20\% in incidence of pulmonary hypertension was observed among different types of ILD when cutoff of mPAP was changed. Conclusion. The new definition helps in a significant increase in the detection of pulmonary hypertension, which certainly helps in earlier detection and better management of patients.

\section{Introduction}

Pulmonary hypertension is a morbid condition that gained recognition in 1973 when the World Health Organization organized its first symposium. The hemodynamic definition was given as mean pulmonary artery pressure $>25 \mathrm{mmHg}$ at rest measured by right heart catheterization [1]. The second symposium was marked by the classification of $\mathrm{PH}$ into five groups based on common pathophysiological findings. The association between pulmonary diseases and $\mathrm{PH}$ was thus formally established and assigned the third group in the classification. Dana Point Classification was given during the $4^{\text {th }}$ symposium and the treatment algorithm updated $[2,3]$. In 2018, the $6^{\text {th }}$ World Symposium on Pulmonary Hypertension was a landmark as a proposal was made to revise hemodynamic definition and set mPAP threshold at a lower value to $\geq 20 \mathrm{mmHg}[4,5]$. This proposal comes in light of the fact that normal mPAP is $14 \mathrm{mmHg} \pm 3.3 \mathrm{mmHg}$. Thus, the values from 20 to $25 \mathrm{mmHg}$ remained a grey zone. Studies have proven that patients with $\mathrm{mPAP} 20-25 \mathrm{mmHg}$ are likely to progress to $\geq 25 \mathrm{mmHg}$ and are at higher risk for morbidity [4]. In our study, we aim to study the effect of the new definition on the prevalence of pulmonary among the patients of ILDs at our tertiary care centre.

\section{Methods}

This cross-sectional study was conducted in the Department of Respiratory Medicine, KGMU, UP, Lucknow, from $1^{\text {st }}$ September, 2018, to $31^{\text {st }}$ August, 2019. Consecutive patients 
diagnosed with interstitial lung diseases who provided written informed consent were included in the study. Approval was obtained from Institutional Ethics Committee. Patients who did not provide consent or had left-sided heart disease were excluded.

239 subjects were enrolled in the study. All were subjected to transthoracic echocardiography, and the following parameters were recorded: tricuspid regurgitation (TR) velocity, right ventricular systolic pressure (RVSP), pulmonary artery acceleration time, right atrial area, right atrial and right ventricular enlargement, tricuspid annular plane systolic excursion (TAPSE), fractional area change (FAC), interventricular septum (IVS) flattening, pericardial effusion, and left ventricular ejection fraction. Right atrial enlargement was said to occur when right atrial area $>18 \mathrm{~cm}^{2}$. TAPSE indicated the longitudinal function of right ventricle. Its normal value was $>1.6 \mathrm{~cm}$ [6]. Mean pulmonary artery pressure was calculated using Mahan's equation: $\mathrm{mPAP}=$ $79-(0.45 * \mathrm{PAT})$ [7]. RVSP was calculated using TR velocity as $\mathrm{RVSP}=4 \mathrm{~V}^{2}+$ right atrial pressure, where $\mathrm{V}$ is the TR velocity. The severity was defined as mild if MPAP was $20-40 \mathrm{mmHg}$ in new definition or $25-40 \mathrm{mmHg}$ in the previous one and moderate and severe when mPAP was 41-55 mmHg and $>55 \mathrm{mmHg}$, respectively [8-10]. Diameter of right pulmonary artery $>16 \mathrm{~mm}$ on chest radiograph was used to define its enlargement [11]. Pro-B-type natriuretic peptide (pro-BNP) and troponin T levels were measured in all the subjects. The statistical analysis was done using SPSS (Statistical Package for Social Sciences) Version 21.0 statistical analysis software. The values were represented in number (\%) and mean \pm SD. The statistical tools employed were mean, standard deviation, chi-square test, Student' $t$ test, analysis of variance (ANOVA), and logistic regression.

\section{Results}

239 subjects were enrolled which comprised of females and had a mean age of years. Most were resident of rural region. Other baseline characteristics are given in Table 1. Majority of the patients fell under the diagnosis of hypersensitivity pneumonitis (HSP) and connective tissue disease-related interstitial lung disease (CTD-ILD). Rest were cases of idiopathic pulmonary fibrosis (IPF), non-IPF idiopathic interstitial pneumonias (IIPs), sarcoidosis, and others. The other ILDs included cases such as combined pulmonary fibrosis and emphysema (CPFE), Langerhans' cell histiocytosis (LCH), occupational lung disease, radiation-induced fibrosis, and unclassified. The distribution of population according to the ILD diagnosis is given in Table 2. When compared gender wise, IPF was more prevalent in males. All the subjects were subjected to transthoracic echocardiography, and statistics was applied using different cutoffs of mPAP. The prevalence of $\mathrm{PH}$ rose from $28.9 \%$ to $46.0 \%$ when $\mathrm{mPAP}>20 \mathrm{mmHg}$ was used to define $\mathrm{PH}$ (Tables 3 and 4). While the prevalence was higher in females, no statistical significance was seen using either definition. Among those with $\mathrm{PH}$, nearly two-thirds were in mild category. The number of severe cases was only two; hence, it was combined with the moderate category while applying statistics. The largest number of cases was seen in HSP subjects, as it was the most prevalent group. Among the different types of ILDs, non-IPF IIPs had the maximum prevalence though the number of subjects was too small (Tables 5 and 6). Echocardiographic parameters were significantly deranged in the moderate-to-severe group only where mean tricuspid regurgitation velocity was $2.53 \mathrm{~m} / \mathrm{s}^{2}$, mean RVSP was $54.7 \mathrm{mmHg}$, and mean diameter of IVC was $21.57 \mathrm{~mm}$ (Tables 7 and 8 and Figure 1). Chest radiograph findings were not so specific as reticulations are seen in ILDs as well. Pulmonary artery was enlarged only in moderate-tosevere cases. Right ventricular hypertrophy and p-pulmonale on ECG were also seen in moderate-severe category. In the lung function test, no significant correlation with was seen with forced vital capacity. Mean pro-BNP was $8582.48 \mathrm{pg} / \mathrm{ml}$ using the older definition group, while it decreased to $5716.68 \mathrm{pg} / \mathrm{ml}$ applying the new cutoff (Figure 2). We ascertained the level of pro-BNP and Trop-T above which all the subjects had $\mathrm{mPAP} \geq 20 \mathrm{mmHg}$. ProBNP $\geq 535.5 \mathrm{pg} / \mathrm{ml}$ was $87.3 \%$ sensitive and $79.1 \%$ specific, while Trop-T $\geq 0.0295 \mathrm{ng} / \mathrm{ml}$ had sensitivity of $73.6 \%$ and specificity of $73.6 \%$ (Table 9 and Figure 3).

\section{Discussion}

The present study was carried out in the Department of Respiratory Medicine, King George's Medical University, Lucknow, for a duration of one year. The prevalence of $\mathrm{PH}$ was estimated among outdoor/indoor ILD patients according to both new and old definition. The lower cutoff of the new definition raised the prevalence by $17 \%$ among our patients.

Among the 239 ILD patients, hypersensitivity pneumonitis $(n=77)$ and CTD-ILD $(n=75)$ comprised most of the study group. Prevalence of other major groups is shown in Figure 1. The higher prevalence of these two subtypes is in accordance with ILD India registry that was the largest study on ILD in the country. The study population had an average age of 52.4 years with female predominance (Table 1). The prevalence of IPF was significantly higher in males (Table 2) as has been previously documented in different international as well as Indian studies [12-14]. While connective tissue disorders are more common in females, associated ILD has been reported more frequently in males $[15,16]$. However, our study had a nearly equal prevalence that is probably due to an overall higher female proportion of the study population. When the older definition of $\mathrm{PH}$ was applied, $28.9 \%$ of the subjects surpassed the diagnostic cutoff (Table 3). Most fell in the range of mild $\mathrm{PH}$, and only two qualified for the severe $\mathrm{PH}$ criteria. Applying the new criteria, the prevalence went up to comprise nearly half of the study population (Table 4). A higher prevalence in Indian scenario could possibly be attributed to a delay in diagnosis of ILD in the peripheral and rural areas that results in unchecked progression of the disease $[17,18]$. Overall, the prevalence is higher in females, which is in accordance with the existing literature, and the values were not significant though $[19,20]$. Female sex hormones have been implicated in the probable mechanism for a higher prevalence. Females have a higher number of estrogen receptors in all the tissues 
TABLE 1: Baseline characteristics of the study population $(n=239)$.

\begin{tabular}{lr}
\hline Characteristics & Statistics \\
\hline Mean age \pm SD (range) in years & $52.4 \pm 13.4(15-88)$ \\
Gender & $141(59.0 \%)$ \\
$\quad$ Female & $98(41.0 \%)$ \\
$\quad$ Male & $136(56.9 \%)$ \\
Residence & $2(0.8 \%)$ \\
$\quad$ Rural & $101(42.3 \%)$ \\
Semiurban & $188(78.7 \%)$ \\
Urban & $51(21.3 \%)$ \\
Nonsmokers & $22.3 \pm 10.1(8-61)$ \\
Smokers/exsmokers & $27.4 \pm 3.4(22-40)$ \\
mPAP \pm SD (range) in mmHg &
\end{tabular}

$\mathrm{SD}$, standard deviation; mPAP, mean pulmonary artery pressure.

TABLE 2: Distribution of subjects according to diagnosis.

\begin{tabular}{lccccc}
\hline \multirow{2}{*}{ S. no. } & \multirow{2}{*}{ Final diagnosis } & \multirow{2}{*}{ No. of patients } & \multicolumn{2}{c}{ Females $(n=141)$} & \multicolumn{2}{c}{ Males $(n=98)$} & No. & $\%$ \\
\hline 1 & & & 77 & 58.4 & 32 \\
2 & Hypersensitivity pneumonitis & 75 & 37 & 49.3 & 38 \\
3 & CTD-ILDs & 30 & 14 & 46.7 & 16 \\
4 & Sarcoidosis & 38 & 11 & 28.9 & 27 \\
5 & IPF & 5 & 4 & 80.7 & 71.1 \\
6 & Non-IPF IIPs & 14 & 7 & 50.0 & 1 \\
\hline
\end{tabular}

$\%$, row-wise; $\chi^{2}=31.136(\mathrm{df}=5) ; p<0.001$. CTD-ILDs, connective tissue disease related interstitial lung diseases; IPF, idiopathic pulmonary fibrosis; IIP, idiopathic interstitial pneumonia; $\mathrm{df}$, degrees of freedom.

TABLE 3: Prevalence and severity of pulmonary hypertension (mPAP $\geq 25 \mathrm{mmHg}$ ).

\begin{tabular}{|c|c|c|c|c|c|c|c|}
\hline \multirow[t]{2}{*}{ S. no. } & \multirow{2}{*}{ Severity of pulmonary hypertension } & \multirow{2}{*}{ Number of patients } & \multirow{2}{*}{ Percentage } & \multicolumn{2}{|c|}{$\begin{array}{c}\text { Female } \\
(n=141)\end{array}$} & \multicolumn{2}{|c|}{ Male $(n=98)$} \\
\hline & & & & No. & $\%$ & No. & $\%$ \\
\hline 1 & No pulmonary hypertension & 170 & 71.1 & 98 & 57.6 & 72 & 42.4 \\
\hline 2 & Mild pulmonary hypertension & 39 & 16.3 & 26 & 66.7 & 13 & 33.3 \\
\hline 3 & Moderate pulmonary hypertension & 28 & 11.7 & 17 & 60.7 & 11 & 39.3 \\
\hline 4 & Severe pulmonary hypertension & 2 & 0.8 & 0 & 0.0 & 2 & 100.0 \\
\hline
\end{tabular}

$\chi^{2}=3.988(\mathrm{df}=3) ; p=0.263 ; \chi^{2}=0.443(\mathrm{df}=1) ; p=0.506$ (for no pulmonary hypertension $(n=170)$ vs. pulmonary hypertension $\left.(n=69)\right)$. mPAP, mean pulmonary artery pressure; $\mathrm{df}$, degrees of freedom.

TABLE 4: Prevalence and severity of pulmonary hypertension (mPAP $\geq 20 \mathrm{mmHg}$ ).

\begin{tabular}{|c|c|c|c|c|c|c|c|}
\hline \multirow{2}{*}{ S. no. } & \multirow{2}{*}{ Severity of pulmonary hypertension } & \multirow{2}{*}{ Number of patients } & \multirow{2}{*}{ Percentage } & \multicolumn{2}{|c|}{$\begin{array}{c}\text { Female } \\
(n=141)\end{array}$} & \multicolumn{2}{|c|}{ Male $(n=98)$} \\
\hline & & & & No. & $\%$ & No. & $\%$ \\
\hline 1 & No pulmonary hypertension & 129 & 54.0 & 72 & 55.8 & 57 & 44.2 \\
\hline 2 & Mild pulmonary hypertension & 80 & 33.5 & 52 & 65.0 & 28 & 35.0 \\
\hline 3 & Moderate pulmonary hypertension & 28 & 11.7 & 17 & 60.7 & 11 & 39.3 \\
\hline 4 & Severe pulmonary hypertension & 2 & 0.8 & 0 & 0.0 & 2 & 100.0 \\
\hline
\end{tabular}

including blood vessels. In general, estrogen has the effect of boosting immunity and promotion of remodeling and fibrosis [21, 22]. The $\beta$ type of estrogen receptors increases the arterial tone and raises the pressure, while the $\alpha$ type has a protective role and prevents fibrosis. The balance between these two types of receptors seems to be responsible for female preponderance $[23,24]$. Both the subjects of severe $\mathrm{PH}$ are males; however, the number is too small to consider it relevant. The prevalence seems higher among IIPs other than IPF and other ILDs as the number of study subjects with these diagnosis was quite low. Nearly $18.2 \%$ of HSP patients had mild $\mathrm{PH}$ that rose to $37.7 \%$ with the revised definition (Tables 5 and 6) Although previous studies have utilized the old definition of $\mathrm{PH}$ to make the diagnosis, a high prevalence has been noted by many. Several studies have reported variable prevalence of pulmonary 
TABLE 5: Diagnosis-wise prevalence and severity of pulmonary hypertension (mPAP $\geq 25 \mathrm{mmHg}$ ).

\begin{tabular}{|c|c|c|c|c|c|c|c|}
\hline \multirow[t]{2}{*}{ Diagnosis } & \multirow[t]{2}{*}{ Total } & \multicolumn{2}{|c|}{$\begin{array}{l}\text { No pulmonary } \\
\text { hypertension } \\
(n=170)\end{array}$} & \multicolumn{2}{|c|}{$\begin{array}{c}\text { Mild pulmonary } \\
\text { hypertension }(n=39)\end{array}$} & \multicolumn{2}{|c|}{$\begin{array}{c}\text { Moderate + severe } \\
\text { pulmonary } \\
\text { hypertension }(n=30)\end{array}$} \\
\hline & & No. & $\%$ & No. & $\%$ & No. & $\%$ \\
\hline $\mathrm{HP}$ & 77 & 52 & 67.5 & 14 & 18.2 & 11 & 14.3 \\
\hline CTD-ILD & 75 & 56 & 74.7 & 11 & 14.7 & 8 & 10.7 \\
\hline Sarcoidosis & 30 & 20 & 66.7 & 5 & 16.7 & 5 & 16.7 \\
\hline IPF & 38 & 31 & 81.6 & 2 & 5.3 & 5 & 13.2 \\
\hline Non-IPF IIP & 5 & 4 & 80.01 & 1 & 20.0 & 0 & 0.0 \\
\hline Others & 14 & 7 & 50.0 & 6 & 42.9 & 1 & 7.1 \\
\hline
\end{tabular}

$\chi^{2}=12.862 ; p=0.232$. CTD-ILD, connective tissue disease-related interstitial lung disease. IPF, idiopathic pulmonary fibrosis; IIP, idiopathic interstitial pneumonia.

TABLE 6: Diagnosis-wise prevalence and severity of pulmonary hypertension (mPAP $\geq 20 \mathrm{mmHg}$ ).

\begin{tabular}{|c|c|c|c|c|c|c|c|}
\hline \multirow[t]{2}{*}{ Diagnosis } & \multirow[t]{2}{*}{ Total, $n=239$} & \multicolumn{2}{|c|}{$\begin{array}{l}\text { No pulmonary } \\
\text { hypertension } \\
\quad(n=110)\end{array}$} & \multicolumn{2}{|c|}{$\begin{array}{l}\text { Mild pulmonary } \\
\text { hypertension } \\
\quad(n=75)\end{array}$} & \multicolumn{2}{|c|}{$\begin{array}{l}\text { Moderate }+ \text { severe } \\
\text { pulmonary } \\
\text { hypertension } \\
(n=30)\end{array}$} \\
\hline & & No. & $\%$ & No. & $\%$ & No. & $\%$ \\
\hline $\mathrm{HP}$ & 77 & 37 & 48.1 & 29 & 37.7 & 11 & 14.3 \\
\hline CTD-ILD & 75 & 42 & 56.0 & 25 & 33.3 & 8 & 10.7 \\
\hline Sarcoidosis & 30 & 19 & 63.3 & 6 & 20.0 & 5 & 16.7 \\
\hline IPF & 38 & 20 & 52.6 & 13 & 34.2 & 5 & 13.2 \\
\hline Non-IPF IIP & 5 & 4 & 80.0 & 1 & 20.0 & 0 & 0.0 \\
\hline Others & 14 & 7 & 50.0 & 6 & 42.9 & 1 & 7.1 \\
\hline
\end{tabular}

$\chi^{2}=6.168 ; p=0.801$. CTD-ILD, connective tissue disease-related interstitial lung disease; IPF, idiopathic pulmonary fibrosis; IIP, idiopathic interstitial pneumonia.

TABLE 7: Association of pulmonary hypertension ( $\mathrm{mPAP} \geq 25 \mathrm{mmHg}$ ) and transthoracic echocardiography, ECG, and chest radiograph findings.

\begin{tabular}{|c|c|c|c|c|c|c|c|c|}
\hline \multirow[t]{2}{*}{ Variable } & \multicolumn{2}{|c|}{$\begin{array}{l}\text { No pulmonary } \\
\text { hypertension } \\
\quad(n=170)\end{array}$} & \multicolumn{2}{|c|}{$\begin{array}{l}\text { Mild pulmonary } \\
\text { hypertension } \\
(n=39)\end{array}$} & \multicolumn{2}{|c|}{$\begin{array}{l}\text { Moderate }+ \text { severe } \\
\text { pulmonary } \\
\text { hypertension } \\
(n=30)\end{array}$} & \multicolumn{2}{|c|}{ ANOVA } \\
\hline & Mean & SD & Mean & SD & Mean & SD & $\mathrm{F}$ & $P$ \\
\hline TR velocity $(\mathrm{m} / \mathrm{s})$ & 1.23 & 0.38 & 1.83 & 0.80 & 2.53 & 1.06 & 63.642 & $<0.001$ \\
\hline RSVP (mmHg) & 26.66 & 5.50 & 42.90 & 5.76 & 54.70 & 13.55 & 249.880 & $<0.001$ \\
\hline Pulmonary AT (ms) & 67.68 & 12.41 & 49.24 & 3.35 & 35.85 & 7.42 & 134.256 & $<0.001$ \\
\hline IVC diameter (mm) & 14.09 & 1.18 & 17.90 & 2.14 & 21.57 & 1.98 & 375.356 & $<0.001$ \\
\hline $\mathrm{RA}$ area $\left(\mathrm{cm}^{2}\right)$ & 9.52 & 2.10 & 14.86 & 3.79 & 17.40 & 3.63 & 151.420 & $<0.001$ \\
\hline TAPSE $(\mathrm{cm})$ & 2.14 & 0.15 & 1.88 & 0.24 & 1.89 & 0.39 & 37.242 & $<0.001$ \\
\hline FAC (\%) & 38.71 & 5.15 & 41.59 & 7.13 & 39.10 & 6.71 & 4.024 & 0.019 \\
\hline \multirow[t]{2}{*}{ LVEF (\%) } & 61.26 & 2.86 & 60.92 & 3.65 & 59.43 & 4.84 & 3.932 & 0.021 \\
\hline & No. & $\%$ & No. & $\%$ & No. & $\%$ & $\chi^{2}$ & $P$ \\
\hline Right atrial enlargement & 0 & 0.0 & 11 & 28.2 & 20 & 66.7 & 109.981 & $<0.001$ \\
\hline Right ventricular enlargement & 0 & 0.0 & 7 & 17.9 & 19 & 63.3 & 107.902 & $<0.001$ \\
\hline Small left chamber & 0 & 0.0 & 0 & 0.0 & 0 & 0.0 & - & - \\
\hline IV septum flattening & 1 & 0.6 & 1 & 2.6 & 2 & 6.7 & 5.950 & 0.051 \\
\hline Pericardial effusion & 0 & 0.0 & 0 & 0.0 & 1 & 3.3 & 6.996 & 0.030 \\
\hline \multicolumn{9}{|l|}{ Chest X-ray } \\
\hline Reticulations & 24 & 14.1 & 3 & 7.7 & 7 & 23.3 & 3.405 & 0.182 \\
\hline Cardiomegaly & 0 & 0.0 & 0 & 0.0 & 9 & 30.0 & 65.153 & $<0.001$ \\
\hline Enlarged PA & 0 & 0.0 & 1 & 2.6 & 5 & 16.7 & 28.942 & $<0.001$ \\
\hline Pruning & 0 & 0.0 & 0 & 0.0 & 1 & 3.3 & 6.996 & 0.030 \\
\hline $\mathrm{RVH}$ & 0 & 0.0 & 1 & 2.6 & 17 & 56.7 & 119.229 & $<0.001$ \\
\hline RAD & 0 & 0.0 & 1 & 2.6 & 21 & 70.0 & 151.962 & $<0.001$ \\
\hline P-pulmonale & 0 & 0.0 & 1 & 2.6 & 13 & 43.3 & 87.747 & $<0.001$ \\
\hline
\end{tabular}

TR, tricuspid regurgitation; RVSP, right ventricular systolic pressure; AT, acceleration time; IVC, inferior vena cava; RA, right atrium; TAPSE, tricuspid annular plane systolic excursion; FAC, fractional area change; LVEF, left ventricular ejection fraction; RV, right ventricle; IVS, interventricle septum; PA, pulmonary artery; ECG, electrocardiogram; RVH, right ventricular hypertrophy; RAD, right axis deviation. 
TABLE 8: Association of pulmonary hypertension $(\geq 20 \mathrm{mmHg})$ and $2 \mathrm{D}$ echo findings, ECG, and X-ray findings.

\begin{tabular}{|c|c|c|c|c|c|c|c|c|}
\hline \multirow[t]{2}{*}{ Findings } & \multicolumn{2}{|c|}{$\begin{array}{l}\text { No pulmonary } \\
\text { hypertension } \\
\quad(n=129)\end{array}$} & \multicolumn{2}{|c|}{$\begin{array}{l}\text { Mild pulmonary } \\
\text { hypertension } \\
\quad(n=80)\end{array}$} & \multicolumn{2}{|c|}{$\begin{array}{c}\text { Moderate + severe } \\
\text { pulmonary } \\
\text { hypertension } \\
(n=30)\end{array}$} & \multicolumn{2}{|c|}{ ANOVA } \\
\hline & Mean & $\mathrm{SD}$ & Mean & SD & Mean & $\mathrm{SD}$ & $\mathrm{F}$ & $P$ \\
\hline TR velocity & 1.15 & 0.28 & 1.63 & 0.69 & 2.53 & 1.06 & 64.863 & $<0.001$ \\
\hline RSVP & 24.84 & 4.06 & 37.50 & 7.73 & 54.70 & 13.55 & 236.263 & $<0.001$ \\
\hline Pulmonary AT & 70.00 & 13.39 & 54.95 & 6.30 & 35.85 & 7.42 & 137.854 & $<0.001$ \\
\hline IVC diameter & 13.91 & 1.04 & 16.25 & 2.41 & 21.57 & 1.98 & 244.722 & $<0.001$ \\
\hline $\mathrm{RA}$ area $\left(\mathrm{cm}^{2}\right)$ & 9.05 & 1.74 & 12.88 & 3.71 & 17.40 & 3.63 & 124.899 & $<0.001$ \\
\hline TAPSE & 2.14 & 0.12 & 2.01 & 0.26 & 1.89 & 0.39 & 19.514 & $<0.001$ \\
\hline FAC (\%) & 38.76 & 5.34 & 40.04 & 6.11 & 39.10 & 6.71 & 1.212 & 0.299 \\
\hline \multirow[t]{2}{*}{ LVEF (\%) } & 61.26 & 2.42 & 61.11 & 3.81 & 59.43 & 4.84 & 3.804 & 0.024 \\
\hline & & $\%$ & No. & $\%$ & No. & $\%$ & $\chi^{2}$ & $P$ \\
\hline RA enlargement & 0 & 0.0 & 11 & 13.8 & 20 & 66.7 & 95.895 & $<0.001$ \\
\hline RV enlargement & 0 & 0.0 & 7 & 8.8 & 19 & 63.3 & 101.260 & $<0.001$ \\
\hline Small left chamber & 0 & 0.0 & 0 & 0.0 & 0 & 0.0 & - & - \\
\hline IV septum flattening & 0 & 0.0 & 2 & 2.5 & 2 & 6.7 & 7.073 & 0.029 \\
\hline Pericardial effusion & 0 & 0.0 & 0 & 0.0 & 1 & 3.3 & 6.996 & 0.030 \\
\hline \multicolumn{9}{|l|}{ Chest X-ray } \\
\hline Reticulations & 17 & 13.2 & 10 & 12.5 & 7 & 23.3 & 2.351 & 0.309 \\
\hline Cardiomegaly & 0 & 0.0 & 0 & 0.0 & 9 & 30.0 & 65.153 & $<0.001$ \\
\hline Enlarged PA & 0 & 0.0 & 1 & 1.3 & 5 & 16.7 & 28.405 & $<0.001$ \\
\hline Pruning & 0 & 0.0 & 0 & 0.0 & 1 & 3.3 & 6.996 & 0.030 \\
\hline RVH & 0 & 0.0 & 1 & 1.3 & 17 & 56.7 & 119.041 & $<0.001$ \\
\hline $\mathrm{RAD}$ & 0 & 0.0 & 1 & 1.3 & 21 & 70.0 & 151.805 & $<0.001$ \\
\hline P-pulmonale & 0 & 0.0 & 1 & 1.3 & 13 & 43.3 & 87.508 & $<0.001$ \\
\hline
\end{tabular}

TR, tricuspid regurgitation; RVSP, right ventricular systolic pressure; AT, acceleration time; IVC, inferior vena cava; RA, right atrium; TAPSE, tricuspid annular plane systolic excursion; FAC, fractional area change; LVEF, left ventricular ejection fraction; RV, right ventricle; IVS, interventricle septum; PA, pulmonary artery; ECG, electrocardiogram; RVH, right ventricular hypertrophy; RAD, right axis deviation.

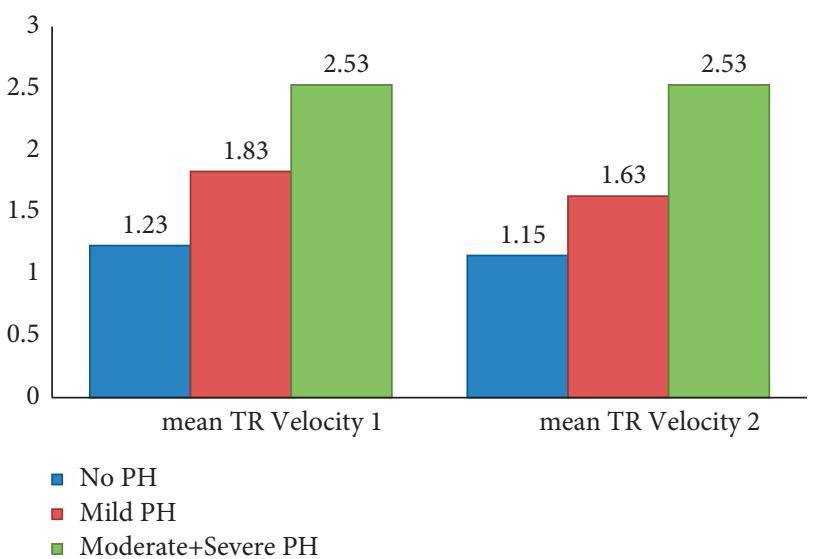

Figure 1: Mean TR velocity $1(\mathrm{~m} / \mathrm{s})$ in subjects diagnosed with older definition and mean TR velocity $2(\mathrm{~m} / \mathrm{s})$ in subjects diagnosed with newer definition.

hypertension varying from $19 \%$ to $31 \%$ in cases of advanced IPF [25-27]. All have reported poorer outcome in patients with pulmonary hypertension. Gradually, the association of other ILDs with pulmonary hypertension was also recognized. A comparative study of pulmonary hypertension prevalence in IPF and NSIP was published in 2006 by Ahmad et al. reporting a poor outcome in the IPF [28]. Pulmonary hypertension is commonly associated with scleroderma and contributes to worse prognosis as has been reported in several studies by Mukerjee et al., Girgis et al.,

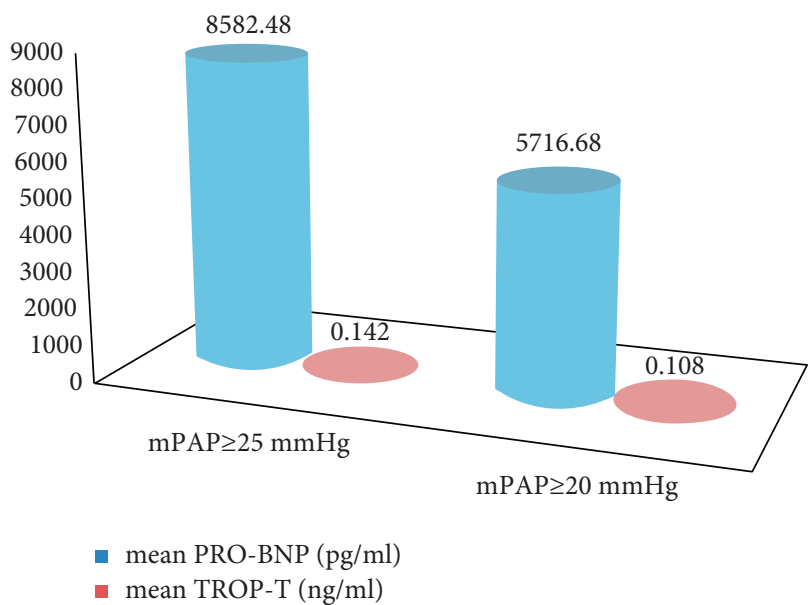

Figure 2: Mean pro-BNP and Trop-T values compared in the two groups.

and Launay et al. [29-31]. In our study, out of 18 patients with CTD-ILD, 10 (55.55\%) had systemic sclerosis.

A high prevalence has been reported previously in CPFE and other rare ILDs such as LCH and lymphangioleiomyomatosis in advanced cases [32-34]. Oliviera RK and Koschel DS have reported a fairly common prevalence of pulmonary hypertension in chronic hypersensitivity pneumonitis ranging from 19\% to 50\% $[35,36]$. The current study has the highest number of HSP subjects which explains the higher number of $\mathrm{PH}$ cases in 
TABLe 9: Prediction of pulmonary hypertension ( $\geq 20 \mathrm{mmHg}$ ) by serum pro-BNP and troponin T values (Figure 3: ROC curve).

\begin{tabular}{lcccc}
\hline Test result variables & Area & Standard error (a) & Asymptotic sig.(b) & \multicolumn{2}{c}{$\begin{array}{c}\text { Asymptotic 95\% confidence interval } \\
\text { Lower bound }\end{array}$} \\
\hline Pro-BNP & 0.918 & 0.017 & $<0.001$ & 0.884 \\
Trop-T & 0.828 & 0.026 & $<0.001$ & 0.777 \\
\hline
\end{tabular}

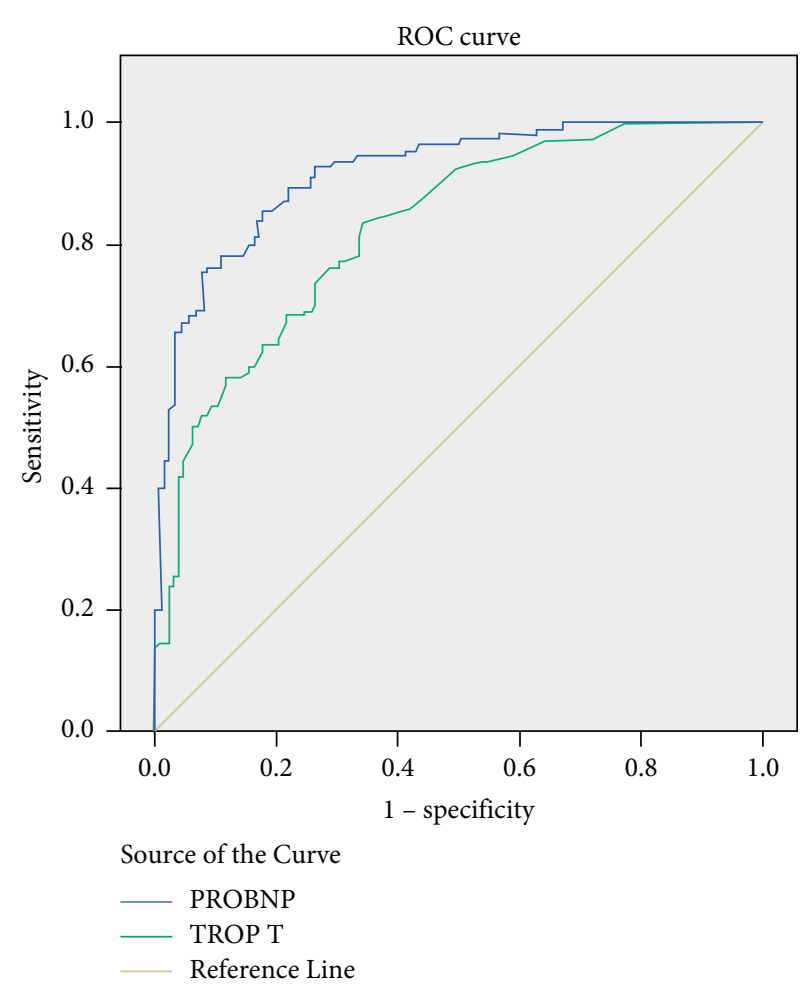

Figure 3: Prediction of pulmonary hypertension $(\geq 20 \mathrm{mmHg})$ by serum pro-BNP and troponin $\mathrm{T}$ values (receiver-operating characteristic curve).

that group. Connective tissue diseases have a high prevalence of $\mathrm{PH}$ as has been demonstrated by several studies [37]. Shirai et al. found out that mixed CTD, systemic lupus erythematosus, and systemic sclerosis constituted $43 \%, 29 \%$, and $19 \%$ of patients of CTD-ILD in their study, respectively [38]. Among Indian studies, Haroon et al. concluded that during early CTD, PH may not be present [39]. Our study shows a $\mathrm{PH}$ prevalence of $25.4 \%$ among CTD patients. Other studies have provided consolidating figures establishing the association of $\mathrm{PH}$ with CTD [40, 41].

In sarcoidosis, pulmonary hypertension has been reported in up to $20 \%$ of patients, and the mechanisms involved are different. Often, the ones with advanced disease are involved [42-44]. Concomitant vasculopathy and inflammatory milieu may also contribute to $\mathrm{PH}$. In the present study, the prevalence of $\mathrm{PH}$ among sarcoidosis subjects varied from $33.4 \%$ (older definition) to $46.7 \%$ (new definition). Most patients report to our tertiary centre in fibrocystic stage in hypoxia, which can account for a higher prevalence of elevated pulmonary artery pressure.

The mean TR velocity in mild cases was $1.83 \mathrm{~m} / \mathrm{s}$, which decreased to $1.63 \mathrm{~m} / \mathrm{s}$ on applying the new definition
(Figure 2). Echocardiography and chest radiography showed significant aberration in moderate to severe $\mathrm{PH}$ patients (Tables 7 and 8). Previous studies vary on correlation of imaging findings with mean pulmonary artery pressure $[45,46]$. Indeed, the diameter of the artery varies not just with the pressure but with blood flow as well. Mean pro-BNP and troponin $\mathrm{T}$ values were elevated in the subjects with $\mathrm{PH}$ (Table 9 and Figure 3). This is in accordance with American Heart Association guidelines [47]. We admit the drawback in our study that the gold standard investigation right heart catheterization was not done. There have been studies that have established the reliability of transthoracic echocardiography as a noninvasive diagnostic modality [48-50].

Thus, in our study, we could conclude that there were a considerable number of subjects with interstitial lung diseases who had their mPAP in the range of $20-25 \mathrm{mmHg}$, and with application of the new definition, the pulmonary hemodynamics got the attention earlier which is likely to impact the management and overall quality of life of such patients.

\section{Conclusion}

We have ascertained the prevalence of pulmonary hypertension among patients of interstitial lung diseases utilizing two different international definitions. The new definition certainly unmasks a large number of subjects who previously fell in the range of elevated pulmonary artery pressure but could not qualify the criteria for diagnosis.

\section{Data Availability}

The data used to support the findings of this study are available from the corresponding author upon request.

\section{Conflicts of Interest}

The authors declare that they have no conflicts of interest.

\section{Authors' Contributions}

Akshyaya Pradhan and Richa Tyagi conceptualized the study and prepared the manuscript. Richa Tyagi, Surya Kant, Anupam Wakhlu, and Akshyaya Pradhan designed the study. Surya Kant, Anupam Wakhlu, and Akshyaya Pradhan defined the intellectual content. Richa Tyagi, Akshyaya Pradhan, Surya Kant, and Jyoti Bajpai performed literature search. Richa Tyagi, Anupam Wakhlu, Akshyaya Pradhan, and Jyoti Bajpai involved in data acquisition. Richa Tyagi, Surya Kant, Anupam Wakhlu, Akshyaya Pradhan, and Darshan Kumar Bajaj performed statistical analysis. Akshyaya Pradhan, Surya Kant, Anupam Wakhlu, and Darshan Kumar Bajaj reviewed and edited the manuscript. 


\section{References}

[1] D. F. Condon, N. P. Nickel, R. Anderson, S. Mirza, and V. A. de Jesus Perez, The 6th World Symposium on Pulmonary Hypertension: What's Old Is New, F1000Res, 2019.

[2] M. M. Hoeper, H. J. Bogaard, R. Condliffe et al., "Definitions and diagnosis of pulmonary hypertension," Journal of the American College of Cardiology, vol. 62, no. 25, pp. D42-D50, 2013.

[3] C. Jardim and D. Waetge, "The importance of the world symposium on pulmonary hypertension," Jornal Brasileiro de Pneumologia, vol. 44, no. 3, pp. 173-174, 2018.

[4] G. Simonneau, D. Montani, D. S. Celermajer et al., "Haemodynamic definitions and updated clinical classification of pulmonary hypertension," The European Respiratory Journal, vol. 53, no. 1, 2019.

[5] M. M. Hoeper and M. Humbert, "The new hemodynamic definition of pulmonary hypertension: evidence prevails," European Respiratory Journal, vol. 53, no. 3, Article ID 1900038, 2019.

[6] L. G. Rudski, W. W. Lai, J. Afilalo et al., "Guidelines for the echocardiographic assessment of the right heart in adults: a report from the American society of echocardiography," Journal of the American Society of Echocardiography, vol. 23, no. 7, pp. 685-713, 2010.

[7] G. Mahan, A. Dabestani, J. Gardin, A. Allfie, C. Burn, and W. Henry, "Estimation of pulmonary artery pressure by pulsed Doppler echocardiography," Circulation, vol. 68, no. 4, p. 367 , 1983.

[8] 2021 https://litfl.com/pulmonary-hypertensionechocardiography/.

[9] A. Afzal, M. Asim Bhatti, and S. Manzoor, "Pulmonary hypertension: an emerging problem in patients undergoing regular hemodialysis," Journal of the College of Physicians and Surgeons Pakistan, vol. 28, no. 8, pp. 594-596, 2018.

[10] $2021 \mathrm{https://emedicine.medscape.com/article/2500073-overview.}$

[11] V. Teichmann, V. Jezek, and F. Herles, "Relevance of width of right descending branch of pulmonary artery as a radiological sign of pulmonary hypertension," Thorax, vol. 25, no. 1, pp. 91-96, 1970.

[12] G. Raghu, H. R. Collard, J. J. Egan et al., “An official ATS/ERS/ JRS/ALAT statement: idiopathic pulmonary fibrosis: evidence-based guidelines for diagnosis and management," American Journal of Respiratory and Critical Care Medicine, vol. 183, no. 6, pp. 788-824, 2011.

[13] L. Nalysnyk, J. Cid-Ruzafa, P. Rotella, and D. Esser, "Incidence and prevalence of idiopathic pulmonary fibrosis: review of the literature," European Respiratory Review, vol. 21, no. 126, pp. 355-361, 2012.

[14] S. Kant, R. Tyagi, A. Wakhlu, A. Parihar, and R. Jaiswal, "Clinicoradiological profile of interstitial lung diseases at a tertiary care center in Northern India: an eight-year study," Indian Journal of Tuberculosis, 2021, In press.

[15] H. Yoo, T. Hino, J. Han et al., "Connective tissue diseaserelated interstitial lung disease (CTD-ILD) and interstitial lung abnormality (ILA): evolving concept of CT findings, pathology and management," European Journal of Radiology Open, vol. 8, Article ID 100311, 2021.

[16] P. Spagnolo, J.-F. Cordier, and V. Cottin, "Connective tissue diseases, multimorbidity and the ageing lung," European Respiratory Journal, vol. 47, no. 5, pp. 1535-1558, 2016.

[17] Z. F. Udwadia and L. Richeldi, "Interstitial lung disease in India. Keep searching and you'll keep finding," American
Journal of Respiratory and Critical Care Medicine, vol. 195, no. 6, pp. 714-715, 2017.

[18] Z. F. Udwadia, T. Sen, and S. K. Jindal, "Interstitial lung disease in a resource limited setting: the case of India," in Interstitial Lung Diseases, R. M. du Bois and L. Richeldi, Eds., European Respiratory Society Monographs, 2009.

[19] M. E. Pugh and A. R. Hemnes, "Pulmonary hypertension in women," Expert Review of Cardiovascular Therapy, vol. 8, no. 11, pp. 1549-1558, 2010.

[20] K. A. Batton, C. O. Austin, K. A. Bruno, C. D. Burger, B. P. Shapiro, and D. Fairweather, "Sex differences in pulmonary arterial hypertension: role of infection and autoimmunity in the pathogenesis of disease," Biology of Sex Differences, vol. 9, no. 1, pp. 15-24, 2018.

[21] K. M. Mair, A. K. Z. Johansen, A. F. Wright, E. Wallace, and M. R. MacLean, "Pulmonary arterial hypertension: basis of sex differences in incidence and treatment response," British Journal of Pharmacology, vol. 171, no. 3, pp. 567-579, 2014.

[22] C. Seillet, N. Rouquié, E. Foulon et al., "Estradiol promotes functional responses in inflammatory and steady-state dendritic cells through differential requirement for activation function-1 of estrogen receptor alpha," The Journal of Immunology, vol. 190, no. 11, pp. 5459-5470, 2013.

[23] H. T. Oakland and P. Joseph, "Sex differences and the role of sex hormones in pulmonary hypertension," Clinics in Chest Medicine, vol. 42, no. 3, pp. 457-465, 2021.

[24] K. Yakimchuk, M. Jondal, and S. Okret, "Estrogen receptor alpha and beta in the normal immune system and in lymphoid malignancies," Molecular and Cellular Endocrinology, vol. 375, no. 1-2, pp. 121-129, 2013.

[25] C. J. Lettieri, S. D. Nathan, S. D. Barnett, S. Ahmad, and A. F. Shorr, "Prevalence and outcomes of pulmonary arterial hypertension in advanced idiopathic pulmonary fibrosis," Chest, vol. 129, no. 3, pp. 746-752, 2006.

[26] G. Raghu, S. D. Nathan, J. Behr et al., "Pulmonary hypertension in idiopathic pulmonary fibrosis with mild-to-moderate restriction," European Respiratory Journal, vol. 46, no. 5, pp. 1370-1377, 2015.

[27] H. F. Nadrous, P. A. Pellikka, M. J. Krowka et al., "The impact of pulmonary hypertension on survival in patients with idiopathic pulmonary fibrosis," Chest, vol. 128, no. 6, pp. 616S-617S, 2005.

[28] S. Ahmad, S. D. Barnett, and O. A. Shlobin, "Comparison of the prevalence of pulmonary arterial hypertension $(\mathrm{PAH})$ in patients with idiopathic pulmonary fibrosis (IPF) and nonspecific interstitial pneumonia (NSIP)," American Journal of Respiratory and Critical Care Medicine, vol. 3, p. S242, 2006.

[29] D. Mukerjee, D. St George, B. Coleiro et al., "Prevalence and outcome in systemic sclerosis associated pulmonary arterial hypertension: application of a registry approach," Annals of the Rheumatic Diseases, vol. 62, no. 11, pp. 1088-1093, 2003.

[30] R. E. Girgis, S. C. Mathai, J. A. Krishnan, F. M. Wigley, and P. M. Hassoun, "Long-term outcome of bosentan treatment in idiopathic pulmonary arterial hypertension and pulmonary arterial hypertension associated with the scleroderma spectrum of diseases," The Journal of Heart and Lung Transplantation, vol. 24, no. 10, pp. 1626-1631, 2005.

[31] D. Launay, L. Mouthon, E. Hachulla et al., "Prevalence and characteristics of moderate to severe pulmonary hypertension in systemic sclerosis with and without interstitial lung disease," The Journal of Rheumatology, vol. 34, pp. 1005-1011, 2007.

[32] V. Cottin, J. Le Pavec, G. Prevot et al., "Pulmonary hypertension in patients with combined pulmonary fibrosis and 
emphysema syndrome," European Respiratory Journal, vol. 35, no. 1, pp. 105-111, 2010.

[33] S. Harari, F. Brenot, M. Barberis, and G. Simmoneau, "Advanced pulmonary histiocytosis $\mathrm{X}$ is associated with severe pulmonary hypertension," Chest, vol. 111, no. 4, pp. 1142-1144, 1997.

[34] V. Cottin, S. Harari, M. Humbert et al., "Pulmonary hypertension in lymphangioleiomyomatosis: characteristics in 20 patients," European Respiratory Journal, vol. 40, no. 3, pp. 630-640, 2012.

[35] R. K. Oliviera, C. A. Pereira, R. P. Ramos et al., "A haemodynamic study of pulmonary hypertension in chronic hypersensitivity pneumonitis," European Respiratory Journal, vol. 44, no. 2, pp. 415-424, 2014.

[36] D. S. Koschel, C. Cardoso, B. Wiedemann, G. Höffken, and M. Halank, "Pulmonary hypertension in chronic hypersensitivity pneumonitis," Lung, vol. 190, no. 3, pp. 295-302, 2012.

[37] A. Caminati, R. Cassandro, and S. Harari, "Pulmonary hypertension in chronic interstitial lung diseases," European Respiratory Review, vol. 22, no. 129, pp. 292-301, 2013.

[38] Y. Shirai, H. Yasuoka, Y. Okano, T. Takeuchi, T. Satoh, and M. Kuwana, "Clinical characteristics and survival of Japanese patients with connective tissue disease and pulmonary arterial hypertension: a single-centre cohort," Rheumatology, vol. 51, no. 10, pp. 1846-1854, 2012.

[39] N. Haroon, R. S. Nisha, V. Chandran, and A. Bharadwaj, "Pulmonary hypertension not a major feature of early mixed connective tissue disease: a prospective clinicoserological study," Journal of Postgraduate Medicine, vol. 51, pp. 104-108, 2005.

[40] D. Ware, V. Sharma, L. Kalekar, A. Kamble, A. Mahajan, and Y. Gokhale, "Higher incidence of pulmonary hypertension in antiphospholipid antibody positive lupus," The Journal of the Association of Physicians of India, vol. 63, pp. 17-20, 2015.

[41] S. Rajagopala and M. M. Thabah, "Pulmonary hypertension associated with connective tissue disease," Indian Journal of Rheumatology, vol. 12, no. 1, pp. 38-47, 2017.

[42] J. M. Bourbonnais and L. Samavati, "Clinical predictors of pulmonary hypertension in sarcoidosis," European Respiratory Journal, vol. 32, no. 2, pp. 296-302, 2008.

[43] T. Handa, S. Nagai, S. Miki et al., "Incidence of pulmonary hypertension and its clinical relevance in patients with sarcoidosis," Chest, vol. 129, no. 5, pp. 1246-1252, 2006.

[44] E. Alhamad, J. Cal, H. Alfaleh, M. Alshamiri, A. Alboukai, and S. Alhomida, "Pulmonary hypertension in Saudi Arabia: a single center experience," Annals of Thoracic Medicine, vol. 8, no. 2, pp. 78-85, 2013.

[45] J. B. Ackman Haimovici, B. Trotman-Dickenson, E. F. Halpern et al., "Relationship between pulmonary artery diameter at computed tomography and pulmonary artery pressures at right-sided heart catheterization. Massachusetts General Hospital Lung Transplantation Program," Academic Radiology, vol. 4, no. 5, pp. 327-334, 1997.

[46] H. Goerne, K. Batra, and P. Rajiah, "Imaging of pulmonary hypertension: an update," Cardiovascular Diagnosis and Therapy, vol. 8, no. 3, pp. 279-296, 2018.

[47] M. E. Liquori, R. H. Christenson, P. O. Collinson, and C. R. Defilippi, "Cardiac biomarkers in heart failure," Clinical Biochemistry, vol. 47, no. 6, pp. 327-337, 2014.

[48] R. E. D’Alto, P. Argiento, R. Vanderpool et al., “Accuracy and precision of echocardiography versus right heart catheterization for the assessment of pulmonary hypertension," International Journal of Cardiology, vol. 168, no. 4, pp. 4058-4062, 2013.
[49] S. Greiner, A. Jud, M. Aurich et al., "Reliability of noninvasive assessment of systolic pulmonary artery pressure by Doppler echocardiography compared to right heart catheterization: analysis in a large patient population," Journal of the American Heart Association, vol. 3, no. 4, Article ID e001103, 2014.

[50] D. X. Augustine, L. D. Coates-Bradshaw, J. Willis et al., "Echocardiographic assessment of pulmonary hypertension: a guideline protocol from the British Society of Echocardiography," Echo Research and Practice, vol. 5, no. 3, pp. G11-G24, 2018. 